\title{
小・中学生の体密度と体構成に関する研究
}

\section{Body Composition and Body Density of Japanese School Children}

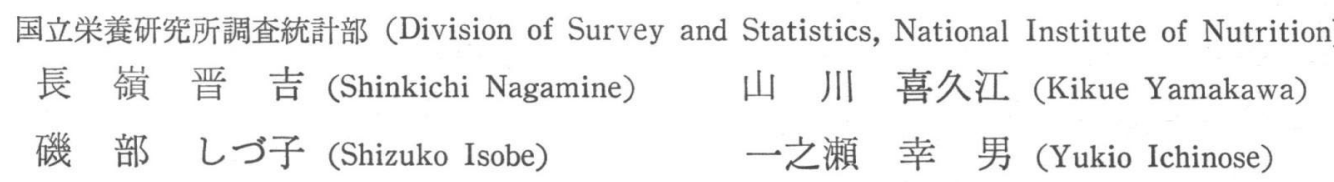

国立栄養研究所栄養生理部 (Division of Nutrition Physiology, National Institute of Nutrition)

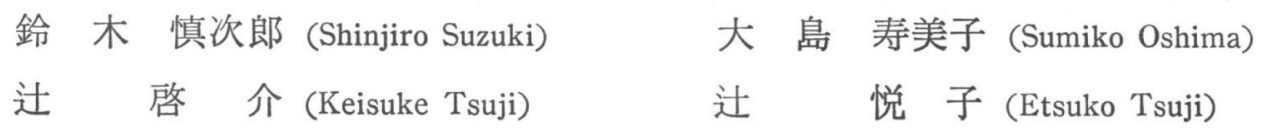

Body densities and skinfold thicknesses of 105 boys and 89 girls aged 9 to 14 years were measured, and the regression equations for predicting the body density from the skinfolds were proposed.

Body density was determined by the water displacement volumetry. The skinfold thicknesses were measured at two sites of triceps and subscapula by using an Eiken-type Caliper (devised in our Institute) calibrated to exert pressure of $10 \mathrm{gm} / \mathrm{mm}^{2}$.

The average values of body density in boys were 1.0621 for $9 \sim 11$ years old and 1.0566 for $12 \sim$ 14 years old and in girls were 1.0490 for $9 \sim 11$ years old and 1.0523 for 12 14 years old (Table 2).

The correlation coefficients between body density and skinfolds were similarly higher in correlation with the triceps skinfold and the combined skinfold of [triceps + subscapula] and with the skinfold index expressed as [skinfold $\times$ body surface $\div$ body weight], as compared with the low coefficient values in subscapular skinfold. The correlations between body density and physique indices of $\mathrm{W} / \mathrm{H}^{2}$ and $\mathrm{W} / \mathrm{H}^{3}$ were lower as compared with the coefficients in the skinfolds (Table 3 ).

The regression equations for predicting the body density from the skinfolds are given in Tables 4, 5 and 6. Among these equations, equation No. 3 for boys and No. 7 for girls are simpler and useful, and equations No. 4 and No. 8 by using the skinfold index are more reliable. The reliability by using the skinfold index lies in eliminating the erroneous element under the influence of individual difference of body height or muscular mass in estimation of the body density and body fat content by the simple use of skinfolds.

日本人の体構成 (Body Composition) に関する一連の研究として, 体密度 (Body Density) の測定と皮下 脂肪厚からの体密度及び体脂肪の予知に関して, 今までに青年男女子 $(18 \sim 23 \text { 歳 })^{1)}$, 思春期男女子 (15 18 歳 $)^{2)}$ について研究を行なってきたが, 今回は, 小・中学生男女（9〜14歳）について体密度の測定を行ない, 皮下脂肪厚と体密度との相関について検討を加えた。

小・中学生年齢層の体密度に関する研究としては, 欧米に扰いては, Parizkova ${ }^{8) 4}$, Heald 5 5), Novak ${ }^{8)}$, Hunt $ら^{7)}$, Seltzer $ら^{8)}$, Young $ら^{9)}$ の報告があるが，日本に捻いては皆無のようである。

本研究の目的は, 日本人小中学生の体構成について体密度の上から研究するとともに, 簡易な皮下脂肪厚の 測定から体密度を予知する式を提示し, ひいては体脂肪及び活性組織量 (Lean Body Mass) を評価するため の基礎的資料を提供するにある。 


\section{対象と測定法}

対象は東京都内の小学生（ 9 〜1歳）男子 47 人, 女子 51 人と中学生（12 14歳）男子 58 人, 女子 38 人で, 測 定は1967年 9 月，体密度，皮下脂肪厚及び体型について行なわれた。

体密度の測定は, 前報2に述べたと同様な方法で, タンクにビューレットを接続した装置と肺活量計との併 用法を用い，排水容積法 (Water displacement volumetry) によって行なわれた。真の体容積を求めるため の肺残気量の測定は, 小中学学年別に男子 28 人, 女子 24 人を抽出して, これらの者について Lundsgaard and Van Slyke ${ }^{10)}$ の方法を用い, 呼気及び肺胞気の分析は Showlander の分析器によって行ない, これにより 得られた残気量と身長との相関より次に示すような回帰方程式を求め, この式を用いて他の対象の肺残気量を 求めた。

残気量の予知式;

男子 : $\mathrm{Y}=14.4 \mathrm{X}-1139(\mathrm{r}=0.64$, S. E. E. $=196.1)$

女子 : $\mathrm{Y}=19.8 \mathrm{X}-2033(\mathrm{r}=0.72$, S. E. E. $=158.6)$

( $\mathrm{Y}=$ 残気量 $\mathrm{m} l, \mathrm{X}=$ 身長 $\mathrm{cm}, \mathrm{S} . \mathrm{E} . \mathrm{E} .=$ 求めるYの標準誤差)

皮下脂肪厚の計測は, 栄研式皮厚計 ${ }^{11}$ を用いて, 国際的に一般に行なわれている右側の上腕背部 (肩峰突起 と肘関節頭との中間位，三頭膊筋上）と肩胛骨下部の二部位に执いて行なわれた。

体表面積の算出には藤本ら ${ }^{12)}$ の式 $\left[\mathrm{A}=\mathrm{W}^{0.444} \times \mathrm{H} \times{ }^{0.663} \times 88.83\right]$ が用いられた。

\section{成 績 と考察}

対象の体型，皮脂厚，体密度 : 対象の身長，体重，下肢長(腸骨前上棘高), 上腕囲の年齢別平均値を示すと 表 1 の 5 K, 身長, 体重は本測定年次の昭和 42 年の文部省学校保健統計 ${ }^{13)}$ の東京都平均値に比較し, 男子の

Table 1 Body Dimensions

\begin{tabular}{lcccccc}
\hline & $\begin{array}{c}\text { Age } \\
\text { (years) }\end{array}$ & No. & $\begin{array}{c}\text { Height } \\
(\mathrm{cm})\end{array}$ & $\begin{array}{c}\text { Weight } \\
(\mathrm{kg})\end{array}$ & $\begin{array}{c}\text { Leg-Length* } \\
(\mathrm{cm})\end{array}$ & $\begin{array}{c}\text { Upper Arm Girth } \\
(\mathrm{cm})\end{array}$ \\
\hline \multirow{6}{*}{ Males } & 9 & 13 & $133.4 \pm 4.58$ & $29.6 \pm 5.58$ & $71.6 \pm 2.55$ & $19.0 \pm 2.52$ \\
& 10 & 16 & $135.1 \pm 4.83$ & $29.1 \pm 3.37$ & $73.9 \pm 3.40$ & $18.7 \pm 1.40$ \\
& 11 & 18 & $144.2 \pm 8.61$ & $36.0 \pm 7.75$ & $80.5 \pm 4.99$ & $20.4 \pm 2.31$ \\
& 12 & 22 & $150.4 \pm 7.11$ & $42.6 \pm 7.74$ & $84.3 \pm 4.23$ & $22.4 \pm 2.67$ \\
& 13 & 17 & $152.9 \pm 8.71$ & $44.9 \pm 9.69$ & $86.3 \pm 4.78$ & $22.4 \pm 2.42$ \\
& 14 & 19 & $162.9 \pm 6.56$ & $56.0 \pm 12.43$ & $88.9 \pm 3.81$ & $25.5 \pm 3.88$ \\
\hline \multirow{4}{*}{ Females } & 11 & 12 & $131.9 \pm 3.71$ & $29.1 \pm 2.77$ & $72.2 \pm 2.70$ & $19.8 \pm 1.24$ \\
& 10 & 17 & $136.8 \pm 6.33$ & $32.0 \pm 6.67$ & $76.0 \pm 3.78$ & $19.8 \pm 2.23$ \\
& 12 & 22 & $142.2 \pm 4.81$ & $35.4 \pm 6.95$ & $78.3 \pm 3.10$ & $19.4 \pm 5.00$ \\
& 13 & $145.7 \pm 6.21$ & $37.3 \pm 5.16$ & $80.3 \pm 3.58$ & $20.9 \pm 1.77$ \\
& 14 & 10 & $154.3 \pm 4.65$ & $46.1 \pm 7.23$ & $84.8 \pm 2.32$ & $22.3 \pm 2.02$ \\
\hline
\end{tabular}

* Height of anterior superior iliac spine.

場合は本対象が身長, 体重ともに高く, 女子は大差ない值を示す。

皮下脂肪厚についてみると（表 2 ）, 上腕部と肩胛骨下部との合計において, 男子では 9 〜1歳が約 15〜19 mm, 12〜14歳が約20〜25 mm，女子では 9〜11歳が約 21〜24 mm, 12〜14歳が 21〜26 mmを示す。これを, 
Table 2 Skinfold Thicknesses and Body Density Values

\begin{tabular}{|c|c|c|c|c|c|c|}
\hline \multirow{2}{*}{\multicolumn{2}{|c|}{$\begin{array}{c}\text { Age } \\
\text { (years) }\end{array}$}} & \multirow{2}{*}{ No. } & \multicolumn{3}{|c|}{ Skinfold Thicknesses (mm) } & \multirow{2}{*}{ Body Density } \\
\hline & & & Triceps & Subscapula & Tricep.+Subscap. & \\
\hline \multirow{6}{*}{ Males } & 9 & 13 & $7.9 \pm 4.60$ & $10.9 \pm 5.20$ & $18.7 \pm 9.69$ & $1.0615 \pm 0.0188$ \\
\hline & 10 & 16 & $5.9 \pm 1.77$ & $8.7 \pm 2.94$ & $14.6 \pm 4.36$ & 1. $0648 \pm 0.0137$ \\
\hline & 11 & 18 & $7.5 \pm 4.80$ & 10. $4 \pm 4.52$ & $17.8 \pm 8.93$ & 1. $0593 \pm 0.0154$ \\
\hline & 12 & 22 & $10.3 \pm 0.85$ & 13. $0 \pm 7.95$ & 23. $4 \pm 16.06$ & 1. $0574 \pm 0.0174$ \\
\hline & 13 & 17 & $9.1 \pm 5.30$ & $11.1 \pm 6.04$ & $20.2 \pm 10.78$ & $1.0580 \pm 0.0134$ \\
\hline & 14 & 19 & $12.8 \pm 9.80$ & $12.8 \pm 7.69$ & $25.6 \pm 17.07$ & 1. $0540 \pm 0.0182$ \\
\hline \multirow{6}{*}{ Females } & 9 & 12 & $9.4 \pm 5.60$ & 11. $2 \pm 3.46$ & $20.6 \pm 8.29$ & $1.0528 \pm 0.0103$ \\
\hline & 10 & 17 & $11.2 \pm 7.72$ & $12.8 \pm 5.79$ & 24. $0 \pm 13.07$ & $1.0460 \pm 0.0151$ \\
\hline & 11 & 22 & $11.1 \pm 5.42$ & $12.1 \pm 4.40$ & $23.2 \pm 9.53$ & $1.0484 \pm 0.0133$ \\
\hline & 12 & 17 & $9.7 \pm 3.63$ & $11.6 \pm 3.87$ & $21.3 \pm 6.78$ & $1.0538 \pm 0.0121$ \\
\hline & 13 & 11 & $10.8 \pm 3.00$ & $12.3 \pm 3.77$ & $23.1 \pm 5.58$ & $1.0548 \pm 0.0124$ \\
\hline & 14 & 10 & $13.1 \pm 2.77$ & $12.8 \pm 2.95$ & $26.0 \pm 5.07$ & $1.0491 \pm 0.0116$ \\
\hline
\end{tabular}

Table 3 Correlation Coefficients Between Body Density and Skinfold Thicknesses and Physique Indices

\begin{tabular}{|c|c|c|c|c|c|}
\hline \multirow{3}{*}{ Body Density } & & \multicolumn{2}{|c|}{ Boys } & \multicolumn{2}{|c|}{ Girls } \\
\hline & & $\begin{array}{c}9 \sim 11 \text { yrs. } \\
(\mathrm{n}=47)\end{array}$ & $\begin{array}{c}12 \sim 14 \text { yrs. } \\
(n=58)\end{array}$ & $\begin{array}{c}9 \sim 11 \text { yrs. } \\
(n=51)\end{array}$ & $\begin{array}{c}12 \sim 14 \mathrm{yrs} \\
(\mathrm{n}=38)\end{array}$ \\
\hline & Triceps & -0.775 & -0.886 & -0.822 & -0.796 \\
\hline \multirow{3}{*}{ Skinfolds } & Subscapular (S) & -0.664 & -0.793 & -0.794 & -0.678 \\
\hline & $(\mathrm{T})+(\mathrm{S})$ & -0.750 & -0.898 & -0.826 & -0.818 \\
\hline & $\frac{(\mathrm{T}+\mathrm{S}) \times \mathrm{m}^{2 *}}{\mathrm{Wt} .}$ & -0.764 & -0.868 & -0.825 & -0.821 \\
\hline \multirow{2}{*}{$\begin{array}{l}\text { Physique } \\
\text { Indices }\end{array}$} & $\left(\mathrm{W}^{* *} / \mathrm{H}^{2 * * *}\right.$ & -0.601 & -0.724 & -0.707 & -0.644 \\
\hline & $\mathrm{W} / \mathrm{H}^{*}$ & -0.567 & -0.720 & -0.661 & -0.675 \\
\hline
\end{tabular}

* (Triceps+Subscapular, $\mathrm{mm}) \times$ Body surface area $\left(\mathrm{m}^{2}\right) \div$ Body weight $(\mathrm{kg}) \times 100$.

** $\mathrm{W}=$ Body weight.

*** $\mathrm{H}=$ Body height.

参考までに長嶺ら ${ }^{14)}$ が昭和37年に計測した東京都学童の皮脂厚 (上腕部+肩胛骨下部), 男子の 9 〜1歳で約 13〜14 mm, 12〜14歳で 12.5〜14 mm, 女子のの〜11歳で 16〜17 mm, 12〜14歳で 19〜27 mm の值に比較 してみると（今回の対象は例数が少なく真の意味での比較にはならないが，皮脂厚の程度を示す意味に抒い て), 本対象の皮脂厚は女子の12〜14歳を除いて他の年齔では男女ともに高い。

体密度は, 男子に拈いては 9 11歳が 1. 059〜1. 065(平均1. 0621), 12〜14歳が 1. 054 1. 058(平均1. 0566), 女子では 9 11歳が 1. 046〜1. 053 (平均1. 0490)，12〜14歳が 1.049〜1. 055 (平均1. 0523）である。これらの 值を長嶺ら $\left.{ }^{2}\right)^{2}$ が計測した成人の体密度男子1. 0694, 女子1. 0472及び思春期 (15 18歳) の男子 1.0728 , 女子 1.0409 に較べると, 本対象の男児は低く，女児は高い值にある。

体密度と皮脂厚及び体格指数との相関 : 体密度と皮脂厚との相関係数をみると表 3 のよ 5 K，上腕 部 皮脂 厚，肩胛骨下部皮脂厚の単一皮脂厚と体密度との相関係数は，上腕 部に括いて男女各年齢にわたって -0.78 
〜 -0.89 の高い係数を示し, 肩胛骨下部に拈ける係数 -0.66 〜 - 0.79 と較べ上腕部において高い。〔上腕部 十肩胛骨下部】皮脂厚との相関係数は男女各年龄にわたってー0.75〜-0.90 とめり，〔(上腕部十肩胛骨下部) $\times$ 体表面積 $\div$ 体重】の皮脂厚指数の体密度に対する相関係数は $-0.76 \sim-0.87 て ゙$, 上腕部単独皮脂厚, 合計 皮脂厚, 皮脂厚指数の三者に拈ける相関係数は同程度に高い值を示している。この点より考えて, 上腕部皮脂 厚の単独計測も中学生以下の児童生徒に招いては体構成の評価に有効であることが考觉られる。

体格指数のカウプ指数 $\left(\mathrm{W} / \mathrm{H}^{2}\right)$ とローレル指数 $\left(\mathrm{W} / \mathrm{H}^{3}\right)$ の体密度との相関係数は, 何れも男女各年齢に拧 いて $-0.60 \sim-0.72$ の範囲にあり，皮脂厚の場合の相関係数に較べ明らかに劣る。

皮脂厚からの体密度の推定：上記の体密度と皮脂厚との相関に基づいて皮脂厚から体密度を予知する回帰方 程式を示すと表 4, 5, 6 の通りである。提示された何れの式を用いてもよいわけであるが，単一部位の皮脂厚 のみから求められた予知式（男子の場合 No.1，2，5，6，女子の場合 No.9，10，13，14）上りは，上腕 部と肩胛骨下部の両部位皮脂厚から求められた予知式（男子に拈いて No. $3 ， 7 ， 17,18$ ，女子に扮いてNo. $11 ， 15 ， 19 ， 20 ）$ の方が一般的に体密度との相関が安定して, 相関度も比較的に高く有利である。しかし, 本

Table 4 Prediction Equations for Body Density from Skinfold Thicknesses in Boys

\begin{tabular}{|c|c|c|c|c|c|}
\hline $\begin{array}{l}\text { Age } \\
\text { (yrs.) }\end{array}$ & Skinfolds & & $\begin{array}{l}\text { Equation } \\
\text { No. }\end{array}$ & Regression Equations & S. E. E.* \\
\hline \multirow{4}{*}{$9 \sim 11$} & Triceps & $\left(\mathrm{X}_{1}\right)$ & 1 & $\mathrm{Y}=1.0904-0.00292 \mathrm{X}_{1}$ & 0.0103 \\
\hline & Subscapula & $\left(\mathrm{X}_{2}\right)$ & 2 & $\mathrm{Y}=1.0807-0.00261 \mathrm{X}_{2}$ & 0.0123 \\
\hline & Triceps+Subscapula & $\left(\mathrm{X}_{3}\right)$ & 3 & $\mathrm{Y}=1.0879-0.00151 \mathrm{X}_{3}$ & 0.0108 \\
\hline & $\frac{(\text { Tricep. }+ \text { Subscap. }) \times \mathrm{m}^{2}}{\text { Wt. }} \times 100$ & $\left(\mathrm{X}_{4}\right)$ & 4 & $\mathrm{Y}=1.0935-0.000559 \mathrm{X}_{4}$ & 0.0106 \\
\hline \multirow{4}{*}{$12 \sim 14$} & Triceps & $\left(\mathrm{X}_{1}\right)$ & 5 & $\mathrm{Y}=1.0819-0.00201 \mathrm{X}_{1}$ & 0.0078 \\
\hline & Subscapula & $\left(\mathrm{X}_{2}\right)$ & 6 & $\mathrm{Y}=1.0731-0.00148 \mathrm{X}_{2}$ & 0.0102 \\
\hline & Triceps +Subscapula & $\left(\mathrm{X}_{3}\right)$ & 7 & $\mathrm{Y}=1.0868-0.00133 \mathrm{X}_{3}$ & 0.0064 \\
\hline & $\frac{\text { (Tricep. }+ \text { Subscap.) } \times \mathrm{m}^{2}}{\text { Wt. }} \times 100$ & $\left(\mathrm{X}_{4}\right)$ & 8 & $\mathrm{Y}=1.0828-0.000417 \mathrm{X}_{4}$ & 0.0086 \\
\hline
\end{tabular}

* Standard errors of the estimate of body density.

Table 5 Prediction Equations for Body Density from Skinfold Thichnesses in Girls

\begin{tabular}{|c|c|c|c|c|c|}
\hline $\begin{array}{l}\text { Age } \\
\text { (yrs.) }\end{array}$ & Skinfolds & & $\begin{array}{c}\text { Equation } \\
\text { No. }\end{array}$ & Regression Equations & S.E. E.* \\
\hline \multirow{4}{*}{$9 \sim 11$} & Triceps & $\left(\mathrm{X}_{1}\right)$ & 9 & $\mathrm{Y}=1.0762-0.00234 \mathrm{X}_{1}$ & 0.0077 \\
\hline & Subscapula & $\left(\mathrm{X}_{2}\right)$ & 10 & $\mathrm{Y}=1.0664-0.00165 \mathrm{X}_{2}$ & 0.0084 \\
\hline & Triceps+Subscapula & $\left(\mathrm{X}_{3}\right)$ & 11 & $\mathrm{Y}=1.0794-0.00142 \mathrm{X}_{3}$ & 0.0065 \\
\hline & $\frac{(\text { Tricep. }+ \text { Subscap. }) \times \mathrm{m}^{2}}{\text { Wt. }} \times 100$ & $\left(\mathrm{X}^{4}\right)$ & 12 & $\mathrm{Y}=1.0782-0.000392 \mathrm{X}_{4}$ & 0.0078 \\
\hline \multirow{4}{*}{$12 \sim 14$} & Triceps & $\left(\mathrm{X}_{1}\right)$ & 13 & $\mathrm{Y}=1.0850-0.00257 \mathrm{X}_{1}$ & 0.0076 \\
\hline & Subscapula & $\left(\mathrm{X}_{2}\right)$ & 14 & $\mathrm{Y}=1.0771-0.00219 \mathrm{X}_{2}$ & 0.0090 \\
\hline & Triceps + Subscapula & $\left(\mathrm{X}_{3}\right)$ & 15 & $\mathrm{Y}=1.0888-0.00153 \mathrm{X}_{3}$ & 0.0069 \\
\hline & $\frac{(\text { Tricep. }+ \text { Subscap. }) \times \mathrm{m}^{2}}{\mathrm{Wt} .} \times 100$ & $\left(\mathrm{X}_{4}\right)$ & 16 & $\mathrm{Y}=1.0967-0.000616 \mathrm{X}_{4}$ & 0.0072 \\
\hline
\end{tabular}

* Standard errors of the estimate of body density. 
Table 6 Multiple Regression Equations for Predicting Body Density

\begin{tabular}{|c|c|c|c|c|c|}
\hline & $\begin{array}{c}\text { Age } \\
\text { (yrs.) }\end{array}$ & $\begin{array}{c}\text { Equation } \\
\text { No. }\end{array}$ & Regression Equations* & $\mathrm{r}^{* *}$ & S. E. E.*** \\
\hline \multirow{2}{*}{ Males } & $\left\{\begin{array}{l}9 \sim 11 \\
0\end{array}\right.$ & 17 & $\mathrm{Y}=1.08547-0.001041 \mathrm{X}_{1}-0.001740 \mathrm{X}_{2}$ & 0.714 & 0.0114 \\
\hline & $\{12 \sim 14$ & 18 & $\mathrm{Y}=1.08017-0.001312 \mathrm{X}_{1}-0.000693 \mathrm{X}_{2}$ & 0.897 & 0.0074 \\
\hline \multirow{2}{*}{ Females } & $\left\{\begin{array}{l}9 \sim 11 \\
0\end{array}\right.$ & 19 & $\mathrm{Y}=1.07435-0.001419 \mathrm{X}_{1}-0.000792 \mathrm{X}_{2}$ & 0.832 & 0.0086 \\
\hline & $\{12 \sim 14$ & 20 & $\mathrm{Y}=1.09070-0.002036 \mathrm{X}_{1}-0.001206 \mathrm{X}_{2}$ & 0.848 & 0.0063 \\
\hline
\end{tabular}

* $\mathrm{Y}$ : Body density, $\mathrm{X}_{1}$ : Triceps skinfold, $\mathrm{X}_{2}$ : Subscapular skinfold.

** $\mathrm{r}$ : Multiple correlation coefficient.

*** S. E. E. : Standard errors of the estimate of body density.

成績に括いて上腕部皮脂厚は体密度と高い相関を示したことから，中学生以下の低年龄層においては No. 1 と No. 5 の式 (男子), No. 9 と No.13の式（女子）子有効に利用し得るすのと考觉られる。

上腕部と肩胛骨下部の両部位皮脂厚を用いて得られた予知式のうち，表 6 飞示した No. 17，18，19，20の 重回帰式は統計的に一般に用いられる式であるが, その重相関係数-0.71〜 -0.90は, 両部位の合計皮脂厚值 と体密度との単相関係数（表 3 ）と差のないことから, また両部位毎の体密度との相関係数間にも大差のない ことから，単回帰式 No. 3，7，11，15は重回㷌式に代って簡便に利用することができる。

皮厚指数〔皮脂厚 $\times$ 体表面積 $\div$ 体重〕からの体密度予知式 No.4, 8 (男子), No. 12, 16 (女子) は, こ の式の意義については前報2)でる述べは上うに，皮脂厚から単純に体密度あるいは体脂肪を見積ることに拈け る身長や筋肉発達度の個人差による影響䛊差を除くという意味で, 特に個人的評価に適した式であると考えら れる。

図 1 及び図 2 に，〔上腕部十肩胛骨下部〕皮脂厚值から体密度及び体脂肪\%を求める回帰直線を示す。体脂 肪\%はBrozek ら ${ }^{15)}$ の式 $[\mathrm{F}(\%)=(4.570 / \mathrm{D}-4.142) \times 100, \mathrm{D}=$ 体密度〕によって計算された。

$$
\begin{aligned}
& \text { 総 括 } \\
& \text { 小・中学生( } 9 \sim 14 \text { 歳) }
\end{aligned}
$$

の男女計 194 人について 体密度を測定し, 体密度 と皮脂厚及び体格指数と の相関, 皮脂厚からの体 密度予知式について検討 を行なった。結果を総括 すると次のようである。

1. 体密度と皮脂厚と の相関は, 上腕部皮脂厚, 〔上腕部 + 肩胛骨下部〕 皮脂厚, 皮脂厚指数〔皮 脂厚 $\times$ 体表面積 $\div$ 体重] に拈いて同程度に高く,

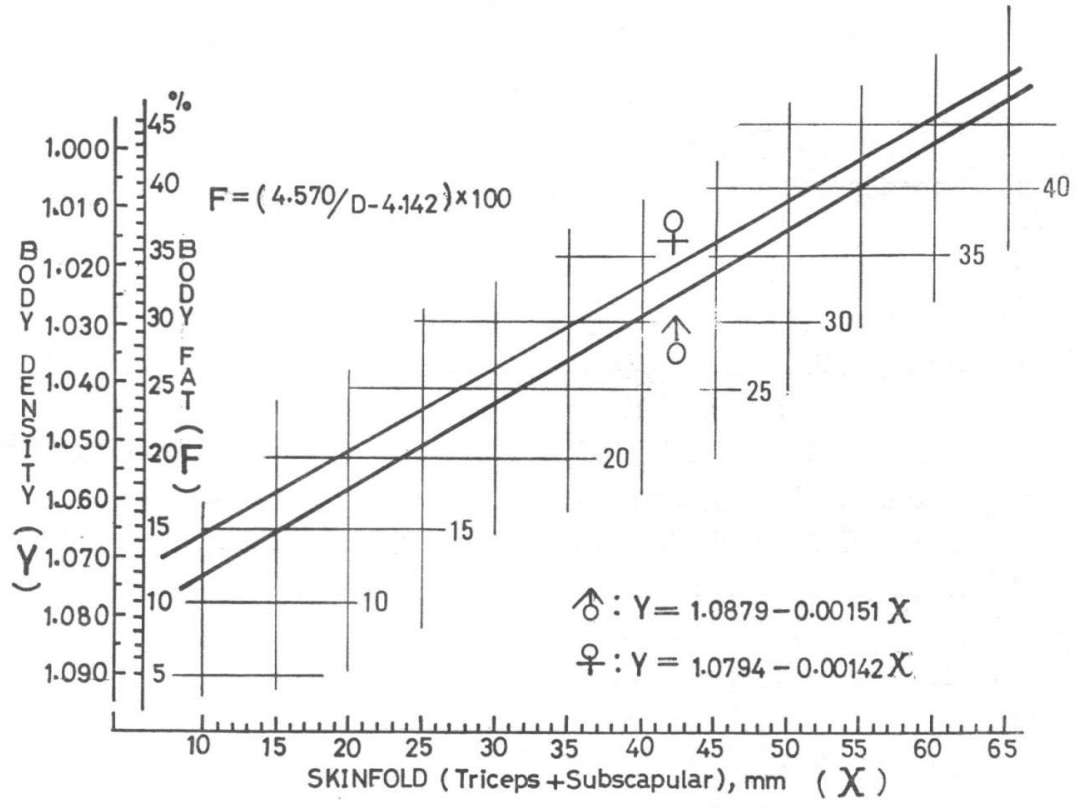

Fig. 1 Nomogram for Prediction of Body Density and Body Fat from Skinfold Thickness (Triceps+Subscapular), 9 11 Years Old Subjects 
男女各年齢にわたって $-0.75 \sim 0.90$ 関相係数 を示した。肩胛骨下部皮 脂厚との相関係数は -0.66〜ー0.79で劣った。

これに対し, 体格指数 （カウプ及びローレル） の体密度に対する相関係 数は, 男女各年齢に扮い $\tau-0.60 \sim 0.72$ のより 低い值であった。

2. 皮脂厚から体密度 を予知する回帰方程式を No. 1 からNo. 20 まで提 示した。これら諸式のう ち，簡便で有効な一般的

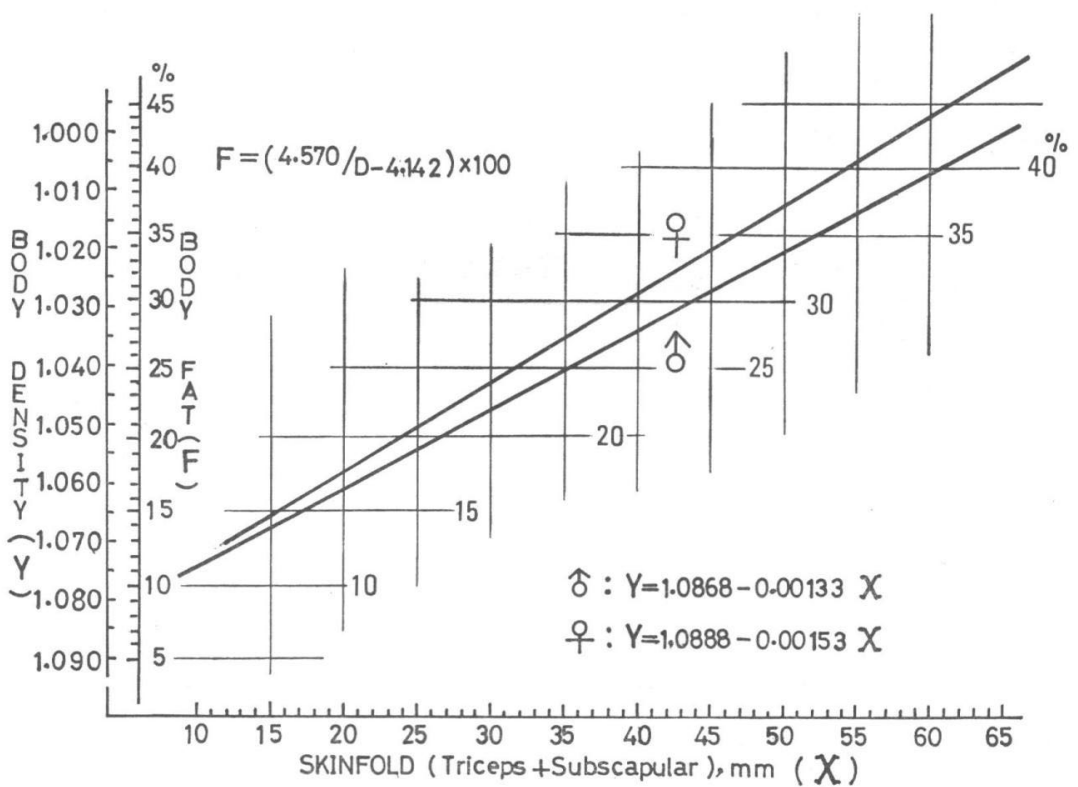

Fig. 2 Nomogram for Prediction of Body Density and Body Fat from Skinfold Thickness (Triceps+Subscapular), 12 14 Years Old Subjects

な式としては男子 9 〜1

歳で No. 3 と No. 17，12〜14歳でNo. 7 と No. 18, 女子の 9 11歳で No. 11と No. 19，12〜14歳でNo. 15, と No. 20の式が適当である。

な拈, 皮脂厚指数を用いた No. 4 (男子 9 〜1歳), No. 8 (男子 12 ～14歳), No. 12 (女子 9 〜11歳), No. 16 (女子12 14歳) の式は計算がやや面倒であるが，より正確な個人評価に適した式と考兄られる。

（本報告の概要は, 昭和 42,43 年度国立栄養研究所研究報告に掲載された。)

\section{文献}

1) Nagamine, S. and Suzuki, S. : Human Biol., 36, 8 (1964)

2) 長嶺, 山川, 他 : 栄養学雑誌, 32, 198 (1974)

3) Parizkova, J. : Metabolism, 10, 794 (1961)

4) Parizkova, J. : J. Appl. Physiol., 16, 173 (1961)

5) Heald, F. P. et al. : Pediatrics, 31, 226 (1963)

6) Novak, L. P. : Ann. N. Y. Acad. Sci., 110, 545 (1963)

7) Hunt, E. E. and Heald, F. P. : Ann. N. Y. Acad. Sci., 110, 532 (1963)

8) Seltzer, C. C., Goldman, R. P. and Mayer, J. : Pediatrics, 36, 212 (1965)

9) Young, C. M., Sipin, S. S.and Roe, D. A. : J. Am. Diet. Ass., 53, 25 (1968)

10) Lundsgaard, C. and Van Slyke, D. D. : J. Exp. Med., 27, 65 (1918)

11) Suzuki, S. and Nagamine, S. : In Proc. Intern. Cong. Sport Sci., 1964, Ed. by K. Kato, Pub. by Jap. Union Sport Sci., Tokyo, 1966, p. 438

12）藤本薰喜, 他 : 厚生省, 日本人の栄養所要量, 昭和 44 年 8 月

13）文部省: 学校保健統計調查報告, 昭和 42 年度

14）長嶺, 加賀, 一之瀬, 磯部: 国立栄養研究所研究報告, 昭和37年 (1962) p. 107

15) Brozek, J., Grande, F., Anderson,J. T. and Keys, A. : Ann. N. Y. Acad. Sci., 110, 113 (1963)

（受付 : 昭和49年10月15日) 